\title{
Ultrasound guided erector spinae plane block provides effective opioid-sparing postoperative visceral pain relief after intussusception surgery: A pediatric case report
}

\author{
Ultrason eşliğinde erektor spina plan bloğu intussepsiyon cerrahisinde etkin visseral \\ ağrı kontrolü ve opioid koruyucu postoperatif analjezi sağlar: Pediyatrik olgu
}

Tayfun AYDIN, Onur BALABAN, Lokman DEMIR

To the Editor,

Erector spinae plane (ESP) block has been documented previously as a part of postoperative multimodal analgesia in pediatric patients for various surgeries. Single injection ESP block may provide prolonged opioid-sparing postoperative analgesia including visceral abdominal pain relief. ${ }^{[1,2]}$ We present a pediatric case of ESP block which provided effective postoperative analgesia after intussusception surgery.

Written informed consent was obtained from the patient's family for publication of this report. A 9-month-old $9.5 \mathrm{~kg}$ patient suffering from intussusception was admitted to the operation room. A surgical reduction was planned after a trial of $C$-arm fluoroscopy guided hydrostatic barium-enema reduction had failed. General anesthesia was planned and ESP block was considered to provide postoperative analgesia and for reduction of opioid usage.

General anesthesia was administered intravenously using propofol $20 \mathrm{mg}$, fentanyl $15 \mu \mathrm{g}$ and rocuronium $10 \mathrm{mg}$. The operation started uneventfully with a mid-right lateral incision involving T10 and T11 dermatomes. The involved intussusception area was at right side of the abdomen (Fig. 1a). Totally $25 \mu \mathrm{g}$ of fentanyl was used in the per-operative maintenance course. The surgery lasted for 2 hours and 10 minutes. After the end of the surgery before we extubat-

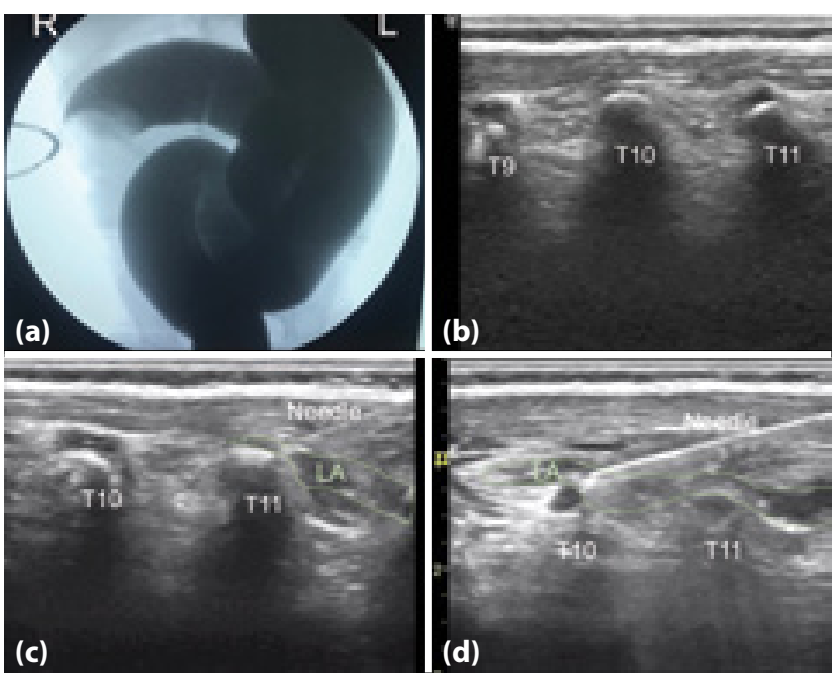

Figure 1. (a) The C-arm fluoroscopy image of the intussusception captured during barium-enema reduction procedure. The barium solution reached to the right side but did not success to recover the intussusception. The involved bowels were at right side of the patient. (b) The ultrasonography image of the vertebrae transverse processes in 9-month-old patient. (c) The ultrasonography image of the injection at T11 transverse process. (d) The ultrasonography image of the injection at $\mathrm{T} 10$ transverse process.

LA: Local anesthetic, R: Right, L: Left.

ed the patient, we performed a single injection ESP block under ultrasound (US) guidance using high frequency linear probe (Logiq, GE Healthcare, IL) at left lateral position. The injection was performed at right side of the patient (Fig. 1b). The needle was advanced from caudal to cephalad direction using inplane technique. Bupivacaine $0.25 \% 3 \mathrm{ml}$ was injected over T11 transverse process (Fig. 1c). We observed

Department of Anesthesiology and Pain Medicine, Kütahya Health Sciences University, Kütahya, Turkey

Submitted: 24.07.2019 Accepted after revision: 18.11.2019 Available online date: 07.07.2020

Correspondence: Dr. Lokman Demir. Kütahya Sağlık Bilimleri Üniversitesi, Anestezi ve Reanimasyon Bilim Dalı, Kütahya, Turkey.

Phone: +90 - 274 - 2316660 e-mail: drlkmndmr@gmail.com

(c) 2020 Turkish Society of Algology 
excessive caudal spread however, the injected solution did not distribute to cephalad direction. Then, the needle was advanced to T10 transverse process without removing out an additional $3 \mathrm{ml}$ of bupivacaine was injected over T10 transverse process (Fig. 1d). After the block, the patient was extubated at the operation room and admitted to the pediatric intensive care unit (PICU).

The patient was followed up postoperatively for 24 hours using revised-FLACC non-verbal pain scale ( $r$ FLACC). The r-FLACC scores were assessed as 0 at $1^{\text {st }}$, $2^{\text {nd }}, 4^{\text {th }}, 6^{\text {th }}, 12^{\text {th }}$ and $18^{\text {th }}$ postoperative hours $(\mathrm{POH})$. The r-FLACC score was 1 at $24^{\text {th }} \mathrm{POH}$. No complications were observed about the ESP block. The patient was discharged from the PICU 4 days after the operation. There was no need of opioids during the postoperative period. Routine administrations of acetaminophen $80 \mathrm{mg}$ was given 4 times a day.

Pediatric postoperative pain management may require a multimodal approach. Data regarding the use of ESP blocks in pediatric patients following abdominal surgery is very rare which are limited to case reports of open duodenoduodenostomy, nephrectomy, open pyeloplasty and laparoscopic cholecystectomy operations..$^{[3-5]}$ Our case is the first report of unilateral bi-level ESP block which provided 24 hours of postoperative both visceral and somatic pain relief and opioid sparing analgesia in 9-month-old patient. Multi-level injection may be a choice when an insufficient spread of local anesthetic is observed.

\section{References}

1. Aksu C, Gürkan Y. Opioid sparing effect of Erector Spinae Plane block for pediatric bilateral inguinal hernia surgeries. J Clin Anesth 2018;50:62-3. [CrossRef]

2. Chin KJ, Malhas L, Perlas A. The Erector Spinae Plane Block Provides Visceral Abdominal Analgesia in Bariatric Surgery: A Report of 3 Cases. Reg Anesth Pain Med 2017;42(3):3726. [CrossRef]

3. Moore R, Kaplan I, Jiao Y, Oster A. The use of continuous Erector Spinae Plane blockade for analgesia following major abdominal surgery in a one-day old neonate. J Clin Anesth 2018;49:17-8. [CrossRef]

4. Aksu C, Gürkan Y. Ultrasound guided erector spinae block for postoperative analgesia in pediatric nephrectomy surgeries. J Clin Anesth 2018;45:35-6. [CrossRef]

5. Thomas DT, Tulgar S. Ultrasound-guided Erector Spinae Plane Block in a Child Undergoing Laparoscopic Cholecystectomy. Cureus 2018;10(2):e2241. [CrossRef] 